\title{
Effects of Allium siculum in ethylene glycol induced kidney stone in male albino rats
}

\author{
Sarbast A. Mahmud*, Aveen R. Khdhr, Abdulsamih M. Taha, Hero A. Qadir, Payam M. Abdulla, \\ Kurdo B. Chato \\ Dept. of Biology, Faculty of Science, Soran University, PO Box 624, Soran, Kurdistan Regional \\ Government, Iraq \\ *Corresponding author: sarbast.bradosty1@gmail.com
}

\begin{abstract}
This study attempts to find out the curative effects of Allium siculum (A. siculum) on ethylene glycol (EG) induced kidney stone in male albino rats. Throughout this study, twenty-two male albino rats were taken and divided into four experimental groups. Group A is a control group, while the rest of the groups, namely group B, C, and D animals, received $1 \%$ EG in water for 14 days, then from day 15 to day 28, the treatment of EG stopped and group C and D animals from day 15 to day 28 received $A$. siculum $(5 \mathrm{~g}$ of dried powder in $100 \mathrm{ml}$ water and $950 \mathrm{~g}$ standard diet) and cystone (2.5 tablets in water and standard diet) respectively. Serum uric acid, creatinine, urea, lipid profile measurements, and glucose were evaluated besides the kidneys' weight and body weight gain. Allium siculum and cystone treatments indicated a significant reduction in serum uric acid, creatinine, urea, glucose, very low-density lipoprotein, and triglyceride compared to EG-treated rats. The kidneys' weight and body weight gains significantly increased in group B compared with A, C, and D. In conclusion: A. siculum has curative effects on ethylene glycol induced kidney stone which resembled the cystone drug.
\end{abstract}

Keywords: Allium siculum; cystone; ethylene glycol; lipid profiles; renal calculi.

\section{Introduction}

Herbal medicine refers to medicinal plants in folk medicine to prevent and treat various diseases, the history of herbal plant applications dated back to the ancient time (Arshad et al., 2020). Herbal phytochemical screening showed numerous bioactive compounds with various biological activities such as alkaloids, polyphenols, essential oils, tannins, quinones, sterols, saponins, etc. (Manzoor et al., 2016). The medicinal plants represent good sources for new, safest, biodegradable, and renewable drugs (Roja et al., 2014), with availability and low costs (Asadbeigi et al., 2014).

Recently, in drug discovery, medicinal plant products were strongly employed (Mohsenzadeh et al., 2016), and they encompass one-third of traditional products (Saki et al., 2014). Patients widely use herbal products to treat joint, skin, gastric (Alvi et al., 2018), hepatic (Strader et al., 2002), respiratory (Blanc et al., 2001), and heart
(Saad et al., 2005) disorders, and also can act as anti-fever, anti-cancer, anti-proliferation (Lim et al., 2019).

In the human body, double bean-shaped organs known as kidneys chemically keep the blood clean (Cunningham et al., 2016). Kidneys play an important role in ride away from the blood by-products through the filtration process for normal body cell functions (Nasri \& Shirzad, 2013). Currently, the kidneys and urinary system problems predominate that led to life-threatening (Dehghan, 2017). However, Jessani et al., 2014, discovered that renal diseases are the main reason for kidney failure, cardiovascular diseases, and premature mortality. Nowadays, the world ratio prevalence of kidney problems is elevating day by day. Among the urinary tract diseases, kidney calculi are the most prevalent kidney problem, leading to strong pain close the flow of urine through the urinary tract, sever hemorrhage, and other risks due to their need 
to take or break by operation (Bahmani et al., 2016). Urolithiasis is a common disorder affecting approximately $12 \%$ of the population, with a recurrence rate of 70$81 \%$ in males and $47-60 \%$ in females (Arya et al., 2017). The stones in the renal form following the sedimentation of constituents in the urinary system (Waugh \& Grant, 2010). Furthermore, the smooth or gagged components of deposited calculi in the kidney appear yellow or brown. Calcium stones are among the most famous types of kidney stones in human and animals which appear in the kidneys than calcium oxalate, calcium phosphate, uric acid, and others (Sunitha et al., 2012). The calcium oxalate urolithiasis model has commonly been used to investigate the influence of urolithiasis on the experimental model in rats. This model is induced by ethylene glycol (EG) as a precursor to oxalate formation (Shekha et al., 2015).

Allium siculum (A. siculum) is a member of subgenus Nectarescordum (Friesen et al., 2006), also known as Nectarescordum siculum, which native to Turkey, Crimea, Greece, Bulgaria, Romania, France, and Italy geographic locations (Altervista Flora Italiana, Aglio della Sicilia, Allium siculum). It has been reported that Allium spp. contain important phytochemicals such as phenolic compounds, flavonoids, volatile oils, diterpenoids, and steroids. Worldwide, Allium spp. are selected as medicinal herbs for curing and treating many health disorders, including cardiovascular problems, diabetes, stomach ulcer, inflammation, cancer, oxidative damage, etc. (Khan et al., 2017). Recently, Vrancheva et al., 2019, investigated that $A$. siculum leaves are the essential origin of flavonoids and phenolic acid, and their potential antioxidant activity exhibited as important health benefits. While Popova et al., 2018, recorded that ethyl benzoate, lipoic acid, calcium, magnesium, and potassium are the main bioactive constituents of $A$. siculum, concerning its use in folk medicine.

The present study was designed to determine the curative effects of shade-dried
A. siculum powder in EG-induced kidney stone in male albino rats. The research work was based on the application of $A$. siculum in ethnopharmacology to treat kidney stones between the local people.

\section{Materials and methods}

\subsection{Animals}

Twenty-two adult male albino rats of about 200-350 g body weight were used in the present study. This work was conducted between November - December 2017 in the animal house at the Department of Biology/ Faculty of Science / University of Soran, Iraq. Rats were bred in the animal house and maintained in the plastic cages $(460 * 30 * 20$ $\mathrm{cm}$ ) bedded with wooden chips. During the experimental period, five to six rats were housed separately in each cage. They were kept under standard laboratory conditions at $22 \pm 2^{\circ} \mathrm{C}$ and exposed to a photoperiod of 12:12 hours light/dark cycle. The rats were bed with standard rat pellets (Mahmud, 2015 ) contained (wheat $66.6 \%$, soya bean $25.6 \%$, sunflower oil $4.4 \%$, lime stone $1.5 \%$, salt $0.63 \%$, methionine $0.158 \%$, choline chloride $0.062 \%$, and trace elements $0.05 \%$ ), with having free access to dichloride water ad libitum.

\subsection{Plant material}

The foliage of $A$. siculum used during the present study was collected during March 2017 from the Hasarost Mountains area near the Judiciary of Choman (about $150 \mathrm{Km}$ to the north of Erbil) Kurdistan Region-Iraq.

The samples were washed using tape water and then shade dried at room temperature for 20-25 days, cut into small pieces, and grounded using an electrical mill (IKAWERKE, GERMAN). The produced powder was stored in cloth bags at $5 \mathrm{oC}$ until use.

\subsection{Experimental design}

This experiment was designed to study the 
curative effects of $A$. siculum on EGinduced kidney stone in male albino rats.Hyperoxalurea and calcium oxalate $(\mathrm{CaOx})$ depositions in the kidney were induced by adding EG to the drinking water to a final concentration of $1 \%$ (Shekha et al., 2015) for all groups except for the control group. Animals were assigned randomly to four different groups continued for 28 days as shown below:

Group A: Control rats $(\mathrm{N}=6)$

Which was supplied with normal water and diet.

Group B: Ethylene glycol $(\mathrm{N}=6)$

Which was received drinking water supplemented with EG 1\% for 14 days, then was given regular water.

\section{Group C: Allium siculum $(\mathrm{N}=5)$}

Which was given $5 \mathrm{~g}$ of dried $A$. siculum powder in $100 \mathrm{ml}$ of water and $5 \mathrm{~g}$ of dried A. siculum powder in $95 \mathrm{~g}$ of standard diet from day 15 after inducing kidney stone.

\section{Group D: Cystone $(\mathrm{N}=5)$}

Which was given 2.5 tablets of Cystone in $100 \mathrm{ml}$ of water and 2.5 tablets in 100 $\mathrm{g}$ of standard diet (Shekha et al., 2015) from day 15 after inducing kidney stone.

\subsection{Collection of blood samples}

At the end of the experiment, the rats were anesthetized with ketamine hydrochloride (40 $\mathrm{mg} / \mathrm{kg}$ ) and xylazine $(10 \mathrm{mg} / \mathrm{kg})$ intraperitoneally. Blood samples were taken by cardiac puncture into chilled tubes with or without ethylene diamine tetraacetic acid (EDTA) $(4.5 \mathrm{mM})$ as an anticoagulant and centrifuged at 3000 rpm for 15 minutes.
2.4.1 Determination of body weight gain and kidney weight

The body weight gain and kidney weight were manually determined in our study.

2.4.2 Determination of uric acid, creatinine and urea

Uric acid, creatinine, and urea in blood were determined using the Cobas c311 instrument, with uric acid, creatinine, and urea test kits (Biolab, Japan) (Hitachi, 2009).

2.4.3 Determination of lipid profiles and blood glucose

Cholesterol, triglyceride (TG), low-density lipoprotein (LDL), high-density lipoprotein (HDL), and glucose in blood were determined by using Cobas c311 instrument, with cholesterol, TG, LDL, HDL, and glucose test kits, respectively (Biolab, Japan) (Hitachi, 2009).

\subsubsection{Determination non-HDL cholesterol}

Non-HDL cholesterol was calculated as total cholesterol minus HDL.

2.4.5. Determination very-low-density lipoprotein (VLDL) level

Very low-density lipoprotein was calculated as TG divided by 5 .

\subsection{Statistical analysis}

All data were expressed as means + standard error (S.E), and statistical analysis was carried out using GraphPad Prism 7 program (Version 7) (GraphPad Software, USA).

The comparisons among groups were done using one-way ANOVA. P-values less than $0.05(\mathrm{P}<0.05)$ were considered statistically significant. In all figures the symbols, $\left(^{*}\right.$, $* *, * * *$ and $* * * *)$ represent that mean of differences are significant at the $0.05,0.01$, 0.001 and 0.0001 levels, respectively. 


\section{Results}

\subsection{Body weight gain}

The body weight gain significantly $(\mathrm{P}<0.0001)$ increased in the control group $(55+1.713)$ as compared with rats treated with EG (6.66+0.843), also cystone and $A$. siculum supplementation significantly $(\mathrm{P}<0.0001)$ and $(\mathrm{P}<0.01)$ respectively elevated body weight gain $(23.33+1.333)$ and $(12.17+1.014)$ respectively in EG treated rats as compared with rats treated with EG (Figure 1).

\subsection{Kidneys weight}

The weight of the kidneys significantly $(\mathrm{P}<0.0001)$ increased in rats treated with EG $(3.682+0.156)$ as compared with the control group $(1.712+0.074)$. Oral administration of $A$. siculum and cystone to EG treated rats significantly $(\mathrm{P}<0.001)$ reduced the kidneys weight $(2.844+0.106)$ and $(2.918+0.125)$ respectively, as compared to rats treated with EG (Figure 2).

3.3 Serum uric acid, creatinine and urea levels

In the rats treated with $E G$, serum uric acid significantly $(\mathrm{P}<0.0001)$ elevated $(6.138+0.328)$ as compared with the value of the control group $(2.37+0.310)$. The increased serum uric acid in EG treated rats was significantly $(\mathrm{P}<0.0001)$ declined after supplementing with $A$. siculum and cystone $(2.028+0.215)$ and $(2.984+0.210)$ respectively (Figure $3 \mathrm{~A}$ ).

The concentration of serum creatinine significantly $\quad(\mathrm{P}<0.0001) \quad$ increased $(0.986+0.040)$ in rats treated with the EG group as compared with the control group $(0.546+0.021)$. Whereas, the A. siculum and cystone significantly $(\mathrm{P}<0.0001)$ prevented the elevation of serum creatinine level $(0.633 \pm 0.022)$ and $(0.61 \pm 0.008)$ respectively in rats treated with $\mathrm{EG}$, as compared with rats treated with EG (Figure 3B).

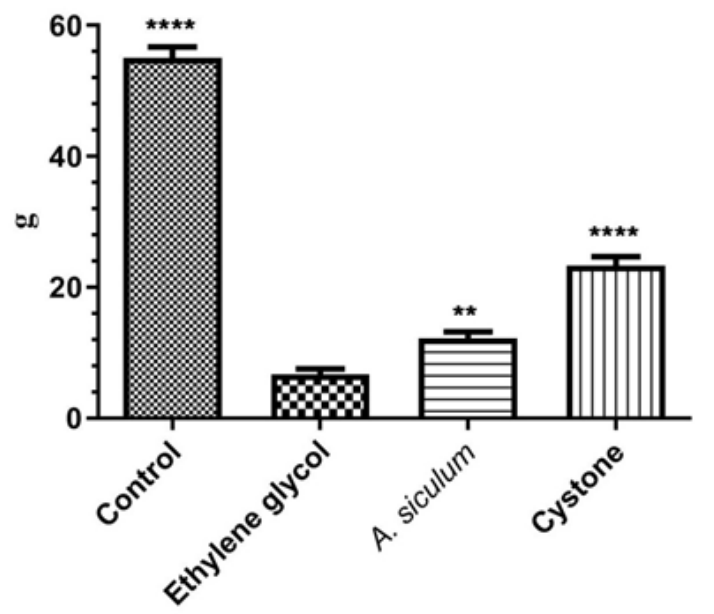

Body Weight Gain

Fig.1. The effect of $A$. siculum on body weight gain.

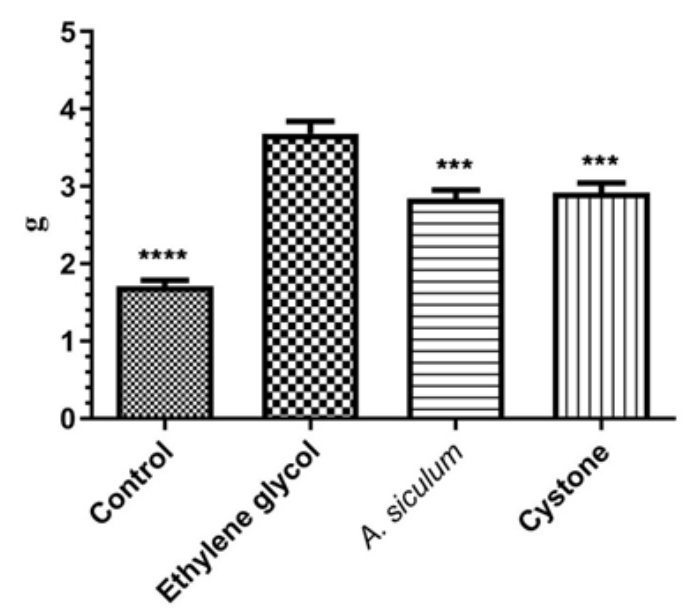

Kidney Weight

Fig. 2. The effect of A. siculum on kidney weight.

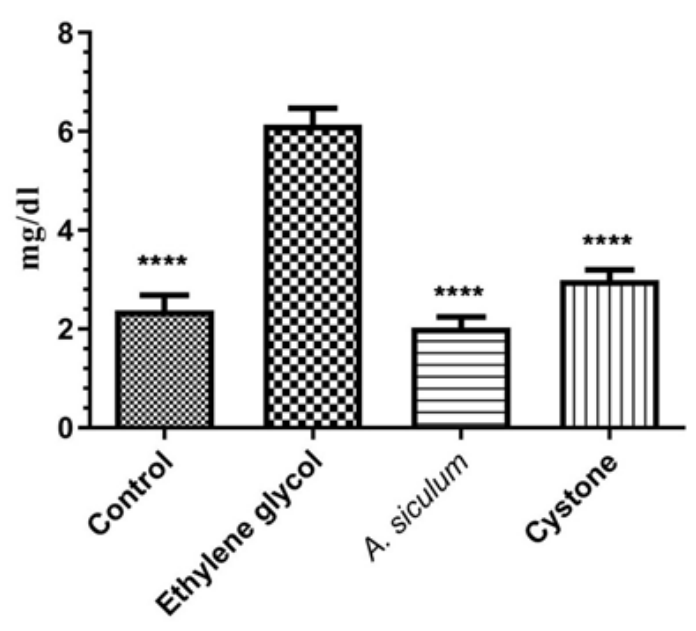

Uric Acid

Fig. 3(a). The effect of $A$. siculum on serum UA. 
Statistical analysis revealed that serum urea level significantly $(\mathrm{P}<0.0001)$ increased in rats treated with EG $(72.17+2.937)$ as compared to the control group $(35.33+1.82)$. On the other hand, in rats treated with EG, serum urea diminished significantly $(\mathrm{P}<0.0001)$ after treating with $A$. siculum and cystone $(42.5+0.957)$ and $(40+2.55)$, respectively, as compared with the EG group (Figure 3C).

3.4 Serum lipid profiles (cholesterol, nonHDL cholesterol, LDL, TG, VLDL, HDL and LDL/HDL ratio) level

The present study approved that the concentration of serum cholesterol, nonHDL cholesterol, and LDL significantly didn't change in the experimental groups (Figure 4 A, B \& C).

The current study showed that the level of serum TG significantly $(\mathrm{P}<0.0001)$ increased in rats treated with EG $(49.50+2.291)$, as compared to the control group (27.00+1.049). Still, each of A. siculum and cystone in rats treated with EG $(\mathrm{P}<0.0001)$ and $(\mathrm{P}<0.001)$ respectively prevented the elevation of TG in the blood $(25.75+0.750)$ and $(36.60+1.288)$ as compared with the EG group $(49.50+2.291)$ (Figure 4D).

Very low-density lipoprotein concentration significantly $(\mathrm{P}<0.01)$ increased in $\mathrm{EG}$ treated rats $(10.88+1.188)$ as compared

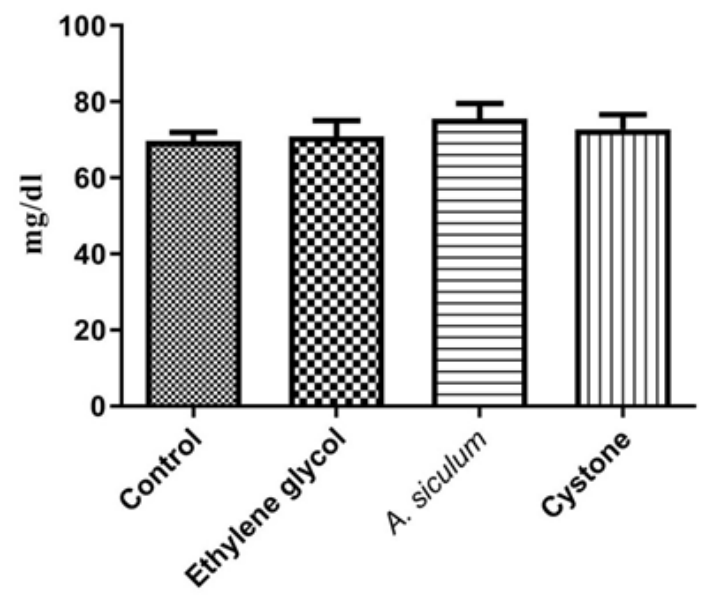

\section{Cholesterol}

Fig. 4(a). The effect of $A$. siculum on serum cholesterol.

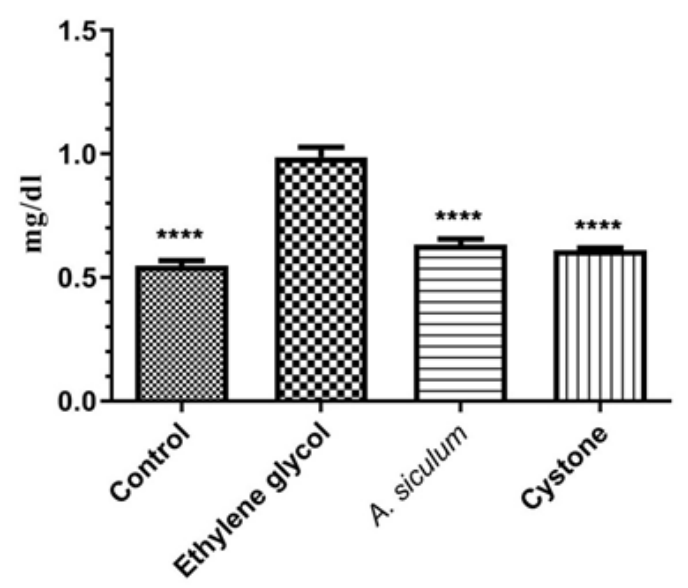

Creatinine

Fig. 3(b). The effect of $A$. siculum on serum creatinine.

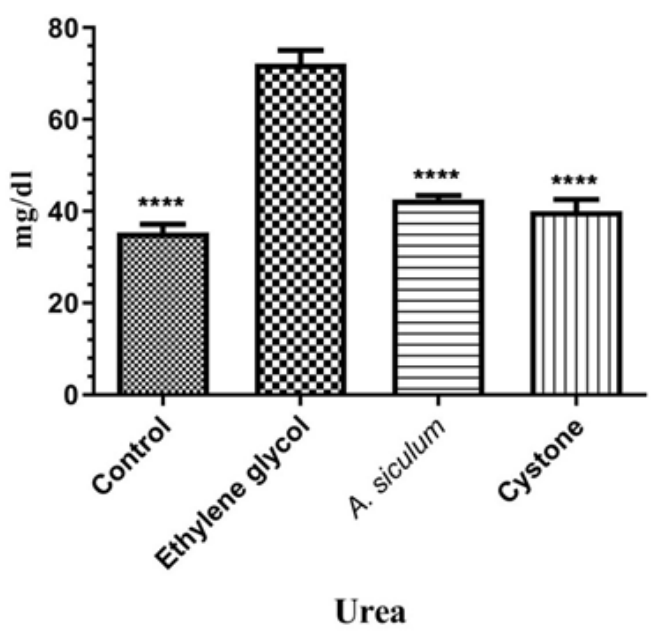

Fig. 3(c). The effect of $A$. siculum on serum urea.

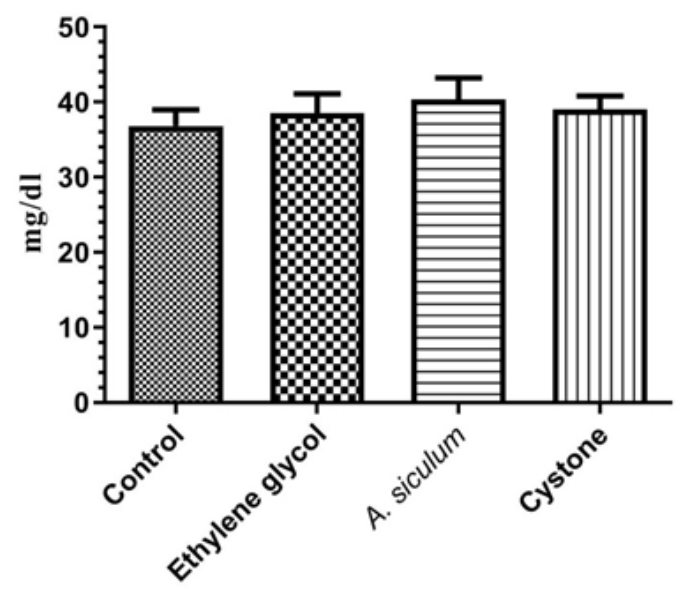

Non-HDL Cholestrol

Fig. 4(b). The effect of $A$. siculum on serum non-HDL cholesterol. 
with the control group $(6.00+0.741)$. A significant reduction $(p<0.001)$ and $(p<0.05)$ respectively in VLDL value was observed by oral administration of $A$. siculum $(5.26+0.505)$ and cystone $(7.32+0.771)$ to rats treated with $\mathrm{EG}$ as compared with rats treated with EG (Figure 4E).

Statistically, it has been discovered that the HDL value non-significantly reduced in EG-treated rats as compared with the control group. Furthermore, oral supplementation of EG-treated rats with A. siculum and cystone reversed the effect of EG on HDL concentration (Figure 4F).

The current study's data statistically revealed that the ratio of $\mathrm{LDL} / \mathrm{HDL}$ in serum significantly didn't change in all experimental groups (Figure 4G).

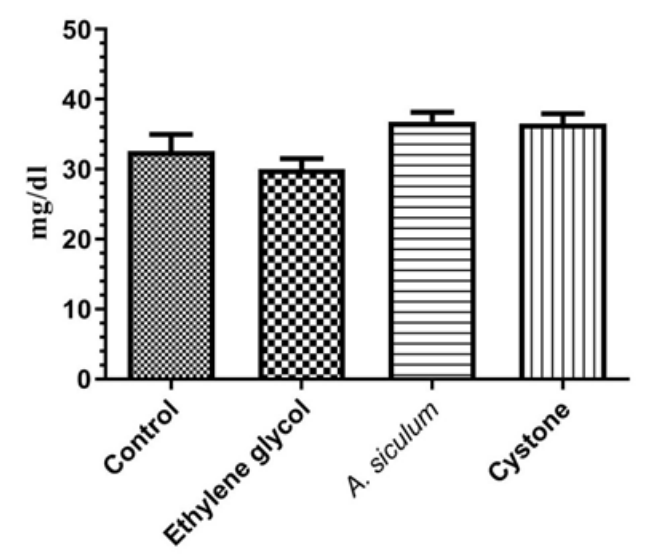

HDL

Fig. 4(f). The effect of $A$. siculum on serum HDL.

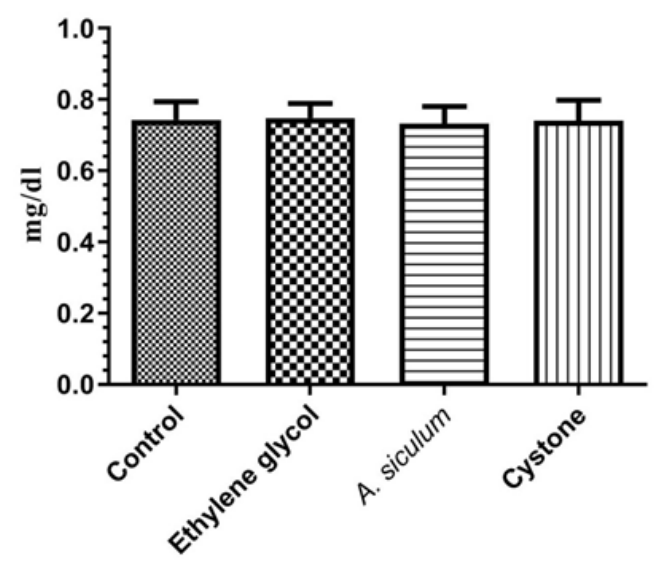

LDL/HDL Ratio

Fig. 4(g). The effect of $A$. siculum on serum LDL/HDL ratio.

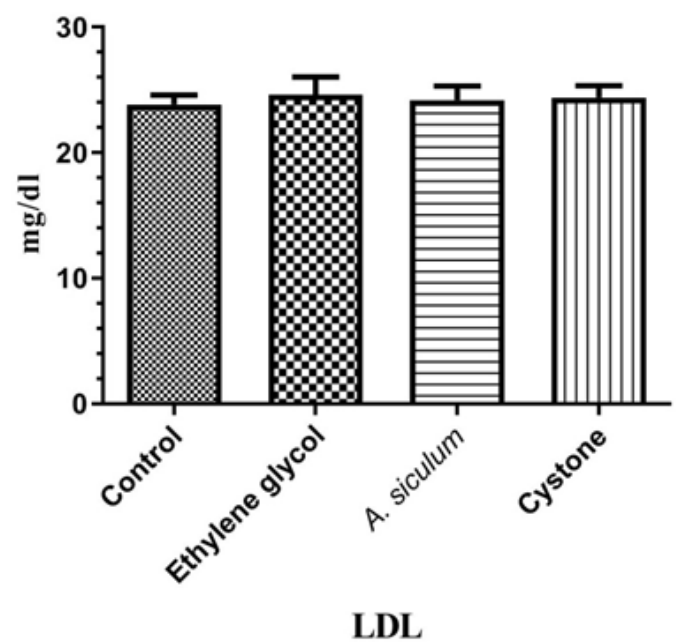

Fig. 4(c). The effect of $A$. siculum on serum LDL.

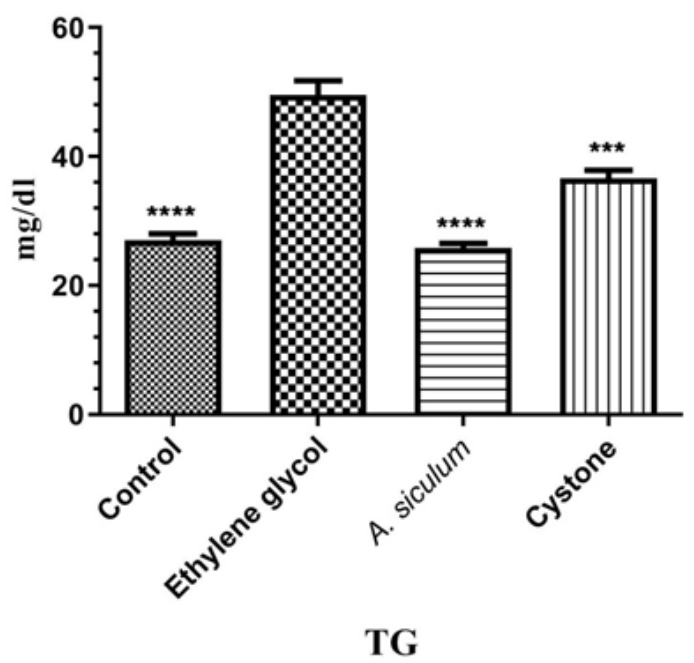

Fig. 4(d). The effect of $A$. siculum on serum TG.

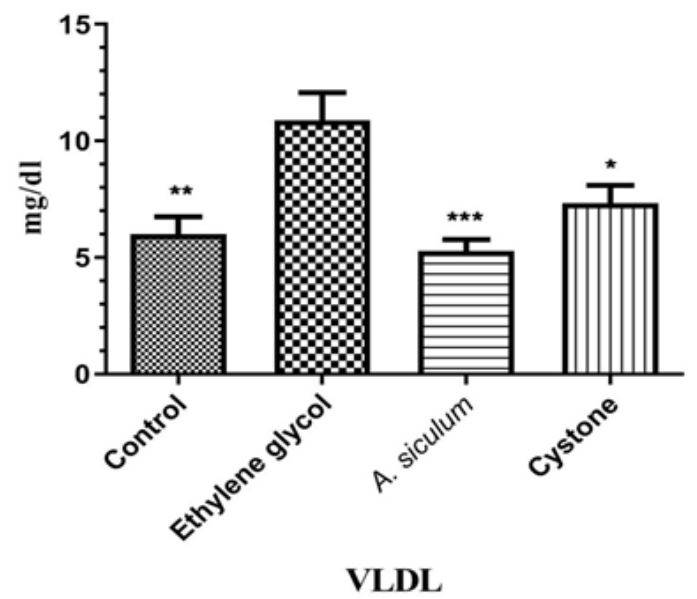

Fig. 4(e). The effect of $A$. siculum on serum VLDL. 


\subsection{Serum glucose level}

The glucose level non-significantly increased in EG-treated rats $(172+9.618)$ compared to the control group $(147.8+5.380)$. On the other hand, oral supplementation of EGtreated rats with $A$. siculum and cystone significantly $(\mathrm{P}<0.0001)$ diminished the glucose level $(113+5.814)$ and $(110.2+6.359)$, respectively, as compared with the EG group $(172+9.618)$ (Figure 5).

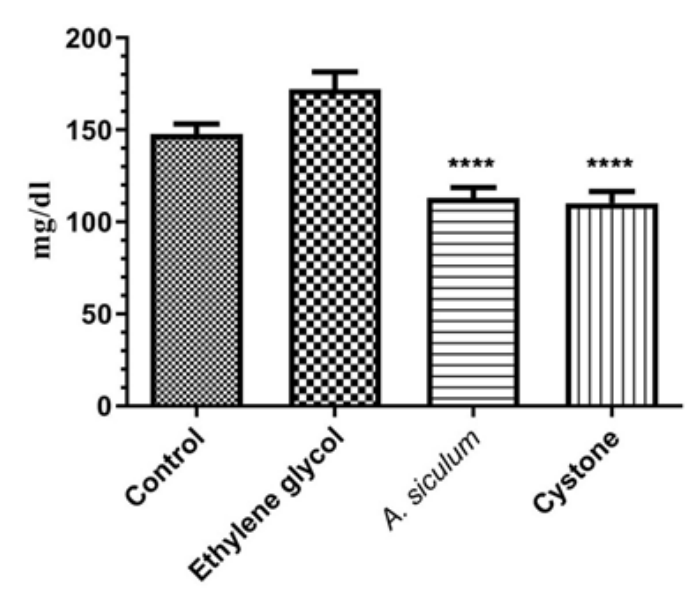

\section{Glucose}

Fig. 5. The effect of $A$. siculum on serum glucose.

\section{Discussion}

This study showed that body weight gain was significantly decreased in EG-treated rats than control rats. Still, in EG-treated rats, supplementation of cystone significantly and $A$. siculum non-significantly reduced the effect of EG on body weight gain. The present study's data revealed the role of $A$. siculum on body weight gain for the first time; thus, no data are available for comparing the results. Our finding is consistent with Golshan et al., 2017, who concluded that EG treatment decreased body weight. On the other hand, Devi et al., 2015, demonstrated that active ingredients in medicinal plants play a crucial role in controlling kidney stone disorders. Furthermore, Grases et al., 2015, discovered that plant polyphenols, with their antioxidant activity, play an essential role in preventing renal calcium oxalate formation. In light of this finding, the $A$. siculum may work via its phenolic acid, flavonoids, and other important phytochemicals like other medicinal plants to control urolithiasis disorder and prevent decreasing body weight.

The present results clearly indicated that kidney weight significantly increased in EG-treated rats compared with control rats. Still, oral administration of cystone and $A$. siculum to rats treated with EG significantly reversed the effects of EG on kidney weight and declined toward control values. These findings supported the observation that EG induced inflammation in the kidney regions and the swollen kidney tubules (Shekha et al., 2015). Furthermore, the data recorded by Golshan et al., 2017, revealed that medicinal plants play an important role in treating kidney stone diseases. Recently, Karimi et al., 2017, was explained that plants with medicinal roles could recovery the kidney from injury. On the other hand, Byahatti et al., 2010, experimentally reported that phenolic compounds could dissolve the calcium oxalate and phosphate renal stones type. Concerning this information, the $A$. siculum may reduce the kidney weight in EG-treated rats via dissolving the stones in kidneys and cure the renal injury through the antioxidant activity of its potential phenolic components.

The present study demonstrated that serum uric acid, creatinine, and urea significantly increased in rats treated with EG compared with control rats, while daily cystone and A. siculum administration to EG treated rats significantly diminished the serum uric acid, creatinine, and urea levels as compared with EG treated rats. The effects of $A$. siculum on kidney stones appeared as the first study. Recent investigations confirmed the present study results that EG increased kidney function parameters through kidney stone formation, and the medicinal plants decline these parameters (Sharma et al., 2017). Also, the obtained data is consistent with Nirumand et al., 2018, concluding that EG treatment increased kidney function parameters. Then they discovered that herbal medicine could normalize the kidney 
biochemical parameters . Furthermore, Byahatti et al., 2010, improved that phenolic compounds could dissolve the calcium oxalate and phosphate renal stones type. The A. siculum may work through its phenolic acid, flavanoids, and other plant bioactive compounds to breaking and dissolving the created stones (calcium oxalate), then renal function measurements returned their original concentrations.

The obtained data from the present study showed that the level of serum TG and VLDL significantly increased in rats treated with EG compared to control rats. In the EGtreated rats, the administration of $A$. siculum and cystone significantly prevented the elevation of TG, VLDL, and glucose levels in the blood compared with EG-treated rats. This is the first study reporting the role of A. siculum in regulating blood TG, VLDL, and glucose levels. Thus no data available to compare the results. The data recorded by Kunnummal Madathodi et al., 2015, supports the current findings that EG leads to acute renal failure, which elevates the glucose in the blood. In addition, Lien et al., 2016, found that the TG concentration significantly increased in kidney stone disease. Recently, Zeni et al., 2017, discovered that polyphenolic compounds could normalize the hyperlipidemic condition. Furthermore, Neerja et al., 2016, demonstrated that Allium sativum and Aloe vera potentially diminished the TG level in hyperlipidemic rats. Some researchers advocated that plant extract significantly diminished the blood glucose in alloxaninduced diabetic rats. The medicinal plants could also reduce the blood glucose level through their phytochemical compounds like alkaloids, flavonoids, tannins, and terpenoids (Ayinla et al., 2015). Regarding the previous data, the A. siculum may normalize the TG, VLDL, and glucose levels by the exact mechanism of the Allium sativum or other medicinal plants via its phenolic compounds concentration, which have potent lipidlowering and hypoglycemic activity.

\section{Conclusion}

From the results of the current study, it has been concluded that $A$. siculum had curative effects in urolithiasis disorder. Allium siculum showed an effective role in increasing body weight gain as reduced by the EG; also, it reversed the effect of EG on kidney weight, which eventually the kidney function tests (uric acid, creatinine, and urea), TG, VLDL, and blood glucose declined toward the normal values.

\section{ACKNOWLEDGEMENTS}

The researchers would like to extend great thanks to Prof. Dr. Mohammad Sajadi, Mr. Chiaye Faqe, Mr. Dler Sulaiman, and Mr. Safeen Husen for their invaluable support during the research. The researchers would also like to express gratefulness to the Department of Biology/ Soran University to support the work partly.

\section{References}

Altervista flora Italiana, aglio della sicilia, Allium siculum. Alvi, A.M.; Iqbal, N.; Bashir, M.A.; Rehmani, M.I.A.; Ullah, Z. et al. (2018). Efficacy of Rhazya stricta leaf and seed extracts against Rhyzopertha dominica and Trogoderma granarium. Kuwait J. Sci., B (3): 64-71.

Arya, P.; Pandey, S. \& Verma, V. (2017). Kidney stones formation and use of medicinal plants as antiurolithiatic agents. Universal Journal of Pharmaceutical Research, 2(4): 42-48.

Arshad, Z.; Abrar, A.; Nosheen, S. \& Mughal, T. (2020). Determining cadmium levels in herbal tooth powders purchased from street markets in Lahore, Pakistan. Kuwait J. Sci., 47 (1): 79-85.

Asadbeigi, M.; Mohammadi, T.; Kopaei, M.R.; Saki, K.; Bahmani, M. et al. (2014). Traditional effects of medicinal plants in 
the treatment of respiratory diseases and disorders: and ethnobotanical study in the Urmia. Asiaan Pas J Ttrop Med, 7(1): S364

Ayinla, T.M.; Owoyele, B.V. \& Yakubu, M.T. (2015). Effect of ethanolic leaf extract of Senna fistula on some haematological parameters, lipid profile, and oxidative stress in alloxan-induced diabetic rats. Niger Journal of Physiological Science, 30: 087093.

Bahmani, M.; Baharvand-Ahmadi, B.; Tajeddini, P.; Rafieian-Kopaei, M. \& Naghdi, N. (2016). Identification of medicinal plants for the treatment of kidney and urinary stones. J Renal Inj Prev, 5(3): 129-133.

Blanc, P.D.; Trupin, L.; Earnest, G.; Katz,P.P.; Yelin, E.H. et al. (2001). Alternative therapies among adults with a reported diagnosis of asthma or rhinosinusitis: data from a population-based survey. Chest Journal, 120(5): 1461-1467.

Byahatti, V.V.; Pai, K.V. \& D'Souza M.G. (2010). Effects of phenolic compounds from Bergenia ciliata (Haw.) Stern. Leaves on experimental kidney stones. Ancient science of life, 30(1): 14-17.

Cunningham, P.; Noble, H.; Al-Modhefer, A.K., \& Walsh, I. (2016). Kidney stones: pathophysiology, diagnosis, and management. British Journal of Nursing, 25(20): 11121116.

Dehghan, S.F. (2017). Oxidative stress, free radicals, kidney disease, and plant antioxidants. Immunopathol Persa, 3(2): 11.

Devi, K.S.; Damayanti, M.; Velmurugan, D. \& Singh, N.R. (2015). Analysis of kidney stones by PXRD and evaluation of the antiurolithic potential of Coix lacryma jobi. International Journal of Scientific and Research Publications, Volume 5: 22503153.
Friesen, N.; Fritsch, R.M. \& Blattner, F.R. (2006). "Phylogeny and new intrageneric classification of Allium (Alliaceae) based on nuclear ribosomal DNA ITS sequences" (pdf). Aliso, B: 372-395.

Golshan, A.; Hayatdavoudi, P.; Hadjzadeh, M.A.; Rad, A.K.; Roshan, N.M. et al. (2017). Kidney stone formation and antioxidant effects of Cynodon dactylon decoction in male wistar rats. AJP, 180-190.

Grases, F.; Prieto, R.M.; FernandezCabot, R.A.; Costa-Bauzá, A.; Tur, F. et al. (2015). Effects of polyphenols from grape seeds on renal lithiasis. Oxidative medicine \& cellular longevity, volume 2015. http:// dx.doi.org/10.1155/2015/813737

Jessani, S.; Bux R. \& Jafar, T.H. (2014). Prevalence, determinant, and management of chronic kidney disease in Karachi, Pakistan-a community-based cross-sectional study. BMC nephrology, 15(1): 1.

Karimi, M.; Naghdi, N.; Haddadi, S.N. \& Bahmani, F. (2017). Medicinal plants used for kidney pain. J. Pharm. Sci. \& Res, 9(5): 542-546.

Khan, S.A.; Jameel, M.; Kanwal, S. \& Shahid, S. (2017). Medicinal importance of Allium species: A current review. International journal of pharmaceutical science and research, 2(3): 29-39.

Kunnummal Madathodi, A.R.; Andrews, M.A. \& Madhavan, I. (2015). Ethylene glycol poisoning; an unusual cause of hyperglycemia: A case report. Asia Pac J Med Toxicol, 4(1): 55-7.

Lien, T.H.; Wu, J.S.; Yang, Y.C.; Sun, Z.J. \& Chang, C.J. (2016). The effect of glycemic status on kidney stone disease in patients with prediabetes. Diabetes Metab J, 40(2): 161-166. 
Lim, P.J.; Gan, C.S. \& Yusof, A. (2019). Lipid-lowering effect of Eurycoma longifolia Jack aqueous root extract in hepatocytes. Kuwait J. Sci., 46(2): 52-58.

Mahmud, S.A. (2015). Phytochemical screening and anti-contracted effected of some active ingredients of crataegus azarolus var. aronia on isolated rats aorta. P.h.D. thesis, Zakho university Kurdistan region, Iraq.

Manzoor, F.; Zafar, A. \& Iqbal, I. (2016). Heterotermesindicola (Wasmann) (Isoptera: Rhinotermitidae) responses to extracts from three different plants. Kuwait J. Sci., 43(3): $128-134$

Mohsenzadeh, A.; Ahmadipour, S.H.; Ahmadipour, S. \& Asadi-Samani, M.A. (2016). Review of the most important medicinal plants effective on cough in children and adults. Der Pharmacia Lettre, 8(1): 90-6.

Nasri, H. \& Shirzad, H. (2013). Toxicity and safety of medicinal plants. J HerbMed Pharmacol, 2: 21-2.

Neerja,J.; Verma,P.; Kumar,V.; Mahdi, F.; Mahdi, A.A. et al. (2016). Antidyslipidemic and antioxidant activity of medicinal plants in rat model of hyperlipidemia. Int J Pharm Sci Res, 7(11): 4579-4587. Doi: 10.13040/ IJPSR.0975-8232.

Nirumand, M.; Hajialyani, M.; Rahimi, R.; Farzaei, M.H.; Zingue, S. et al. (2018). Dietary plants for the prevention and management of kidney stones: preclinical and clinical evidence and molecular mechanisms. International Journal of molecular science, 1-24.

Popova, A.; Mihaylova, D. \& Alexieva, I. (2018). GC-MS chemical composition of volatile oil and mineral element content of Allium ursinum and Nectaroscordum siculum. Pak. J. Bot., 50(6): 2351-2354.
Roja, N.M.; Satyavani, S.; Sadhana, B.; Nikitha, T. \& Padal, S.B. (2014). A review on ethanomedicinal plants having antidiabetic activity in north coastal Andhra Pradesh, India. BMR Journals, 1(1): 1-9.

Saad, B.; Azaizeh, H. \& Said, O. (2005). Tradition and perspectives of Arab herbal medicine: a review. Evidence-based complementary and alternative Medicine, 2(4): 475-479.

Saki, K.; Bahmani, M. \& Rafieian-Kopaei, M. (2014). The effect of most important medicinal plants on two important psychiatric disorders (anxiety and depression)-a review. Asian Pac J Trop Med, 7: 34-42.

Sharma, I.; Khan, W.; Parveen, R.; Alam, M.J.; Ahmad, I. et al. (2017). Antiurolithiasis activity of bioactivity guided fraction of Bergenia ligulata against ethylene glycol induced renal calculi in rat. BioMed Research International, Vol. 2017. doi. org/10.1155/2017/1969525

Shekha, M.S.; Ismail, T.F. \& Aziz, F.M. (2015). Anti-urolithiatic and anti-oxidant effects of fenugreek on ethylene glycolinduced kidney calculi in rats. JJBS, 159-163.

Strader, D.B.; Bacon, B.R. \& Lindsay, K.L. (2002). Use of complementary and alternative medicine in patients with liver disease. The American journal of gastroenterology, 97(9): 2391-2397.

Sunitha, J.; Asha, S. \& Taju, G. (2012). Protective effect of spirulina on ethylene glycol induced urolithiasis in rats. Inter Res J Pharmacy, 3: 444-448.

Vrancheva, R.; Stoyanova, M.; Mihaylova, D.; Aneva, I.; Deseva, I. et al. (2019). Polyphenol profile and antioxidant activity of wild-growing populations of Nectaroscordum siculum ssp. bulgaricum (Janka) Stearn in Bulgaria. InternationalFood Research Journal, 26(5): 1635-1640. 
Waugh, A. \& Grant, A. (2010). Anatomy and physiology in health and illness, $11^{\text {th }}$ edn. Edinburgh: Churchill Livingstone.

Zeni, A.L.B.; Moreira, T.D.; Dalmagro, A.P.; Camargo, A.; Bini, L.A. et al. (2017). Evaluation of phenolic compounds and lipidlowering effect of Morus nigra leaves extract. Anais da Academia Brasileira de Ciências, 89(4): 2805-2815.

$\begin{array}{lr}\text { Submitted: } & 31 / 05 / 2020 \\ \text { Revised: } & 20 / 05 / 2020 \\ \text { Accepted: } & 23 / 05 / 2020 \\ \text { DOI: } & 10.48129 / \text { kjs.v48i3.8906 }\end{array}$

